Article

\title{
Understanding Capabilities, Functionings and Travel in High and Low Income Neighbourhoods in Manila
}

\author{
Robin Hickman ${ }^{1, *}$, Mengqiu Cao ${ }^{1}$, Beatriz Mella Lira ${ }^{1}$, Alexis Fillone ${ }^{2}$ and Jose Bienvenido Biona ${ }^{2}$ \\ ${ }^{1}$ Bartlett School of Planning, University College London, London, WC1H ONN, UK; E-Mails: r.hickman@ucl.ac.uk (R.H.), \\ mengqiu.cao.13@ucl.ac.uk (M.C.), beatriz.lira.14@ucl.ac.uk (B.M.L.) \\ 2 Center for Engineering and Sustainable Development Research, De La Salle University, 1004 Manila, The Philippines; \\ E-Mails: fillonea@dlsu.edu.ph (A.F.), jose.bienvenido.biona@dlsu.edu.ph (J.B.B.) \\ * Corresponding author
}

Submitted: 28 June 2017 | Accepted: 24 October 2017 | Published: 28 December 2017

\begin{abstract}
Transport plays an important role in helping people to access activities and participate in life. The availability of transport networks, the modes available, new infrastructure proposals, and the type of urban development can all impact on and change activity participation, and hence contribute to social equity in the city. This article uses surveys in low and high income neighbourhoods in Manila, the Philippines, to assess the social equity implications of differential access to transport. The analysis demonstrates how the theoretical framework of the Capability Approach (Nussbaum, 2003; Sen, $1985,1999,2009)$ can be used to assess what individuals might be able to access (capabilities) versus their actual travel (functionings). The spatial patterns of travel and access to activities are assessed, demonstrating significant differences by gender, age, income and neighbourhood, in terms of travel mode and cost of travel; health, physical and mental integrity; senses, imagination and thoughts; reasoning and planning; social interaction; natural environment; sustainable modes; and information. This approach to assessing the transport dimensions of social equity offers much potential, based not only on access to resources or consumption of mobility, but also in the opportunities that people have in relation to their activity participation. The case study context is also informative, with Manila providing an example of an Asian city with high levels of private car usage, high levels of congestion, and large spatial and income differentials in travel and associated social equity.
\end{abstract}

\section{Keywords}

Capability Approach; income; Manila; mobility; neighbourhood; social equity; transport; travel

\section{Issue}

This article is part of the issue "Regional and Urban Mobility: Contribution to Social Inclusion", edited by Janet Stanley (University of Melbourne, Australia) and John Stanley (University of Sydney, Australia).

(C) 2017 by the authors; licensee Cogitatio (Lisbon, Portugal). This article is licensed under a Creative Commons Attribution 4.0 International License (CC BY).

\section{Introduction}

The first Human Development Report (United Nations Development Programme, 1990) was published almost three decades ago, and since there have been various attempts to improve levels of social equity, over many contexts internationally. The focus has been on putting people at the centre of the development process, i.e., aiming to create the conditions for people to enjoy long, healthy and rewarding lives, rather than simply pursuing increases in Gross Domestic Product (GDP). But understanding levels of social equity, the multi-dimensionality of this, and the potential solutions, has proved complex. Social equity is viewed as a fair access to opportunities, livelihood, education, and resources, with social justice as the fair and just relation between the individual and society, including the distribution of wealth, opportunities and social privilege (Mella Lira \& Hickman, 2017). Spatial patterns of social equity still vary greatly between and within countries-and it is not always ob- 
vious what should and can be improved and how. Some countries and cities have become more inequitable over the last few decades, with inadequate resources available to maintain even minimum standards of living. Inequity is now widely seen as moving beyond the accumulation of wealth, incorporating issues such as participation in activities, employment, education, and other factors, such as literacy, life expectancy, health, and wellbeing. Perhaps there has been less discussion concerning the role of transport in supporting social equity; however, effective transport seems fundamental to many of the issues being faced-with transport required to facilitate participation in activities. Travel is not usually an end in itself, but provides one of the means to access what people value. In addition, active transport, through walking and cycling, has many direct health benefits (Woodcock et al., 2009).

This article uses the Capabilities Approach (CA), developed by Amartya Sen (Sen, 1985, 1999, 2009) as a theoretical framework to understand the differences in travel and participation in activities. It applies CA, using surveys in high and low income neighbourhoods in Metro Manila, the Philippines. ${ }^{1}$ The contribution of the article is to understand the opportunities that people have and aspire to, and what they actually achieve, relative to accessing activities, and to examine how this is distributed by gender, age, income and neighbourhood. These issues are seen as important in a context such as Manila, where the activities that individuals might be able to or like to access, relative to their actual travel, are likely to be very uneven across population cohorts and spatially. Individuals do not always take up the theoretical opportunities on offer. The use of the accessibility that is available, via different transport networks, might not be straightforward-with some modes not used for issues such as cost, status, comfort and safety. The political and cultural structure of society is critical to travel and social equity-enabling only a limited set of choices at the individual level. As Sen $(2009$, p. 227) states:

In assessing our lives, we have reason to be interested not only in the kind of lives we manage to lead, but also in the freedom we actually have to choose between different styles and ways of living.

The article hence develops an approach to apply CA in relation to travel, assuming that the context of Manila might be associated with unequal access to travel and participation in activities. Reflections are given on the implications of using CA as a framework for assessing the social equity impacts of transport systems.

\section{The Capabilities Approach and Travel}

Transport can be an important factor in helping to develop socially-equitable societies, with the different types of infrastructure, such as highway, public transport or walking and cycling networks, tending to be used by different cohorts in society. A diverse literature has examined the potential relationships between transport and social equity, social exclusion, and wider issues such as social capital and well-being, including the barriers to access experienced by different groups (such as Church, Frost, \& Sullivan, 2000; Currie et al., 2009; Currie \& Stanley, 2008; Delbosc \& Currie, 2011; Lucas, 2004, 2012; Preston \& Rajé, 2007; Social Exclusion Unit, 2003; Stanley, Hensher, Stanley, \& Vella-Brodrick, 2011). Accessibility analysis and planning have been usefully applied in practice, particularly in Global North contexts, to examine the impacts of transport strategies and projects (Ashiru, Polak, \& Noland, 2003; Dong, Ben-Akiva, Bowman, \& Walker, 2006; Geurs, Boon, \& Van Wee, 2009; Geurs, Zondag, De Jong, \& De Bok, 2010; Hansen, 1959).

CA offers a complementary way of examining these issues, focusing on the opportunities that people have, and the realisation of these opportunities, in accessing activities. There is much use of CA in wider fields, notably in development studies (see Comin, Qizilbash, \& Alkire, 2008, and many others); but little in transport planning, despite much potential for application. Some research is beginning to emerge, in developing the conceptual framework for use in transport (Beyazit, 2011; Hananel \& Berechman, 2016; Martens, 2017; Mella Lira \& Hickman, 2017; Nahmias-Biran, Martens, \& Shiftan, 2017; Nordbakke \& Schwanen, 2014), and applying this through case studies (Nordbakke, 2013; Ryan, Wretstrand, \& Schmidt, 2015).

The central concepts used in CA are:

- Capabilities: representing the "alternative combinations of doings and beings that are feasible to achieve", i.e., what real opportunities are available for people to do and to be (Sen, 1999, p. 75);

- Functionings: the "various things a person may value doing and being" (Sen, 1999, p. 75), with the realised functionings representing what a person actually achieves and how. These might include elementary activities, such as being adequately nourished, being in good health, avoiding early morbidity; to more complex activities or personal states, such as taking part in activities and community life, having self-respect and being happy.

In transport, this distinction can be useful in allowing us to understand the opportunities available in a particular context and also how this relates to actual participation in activities. The realised functioning element (what a person actually does) is perhaps the easiest to measure, represented by the actual travel and participation in activities. The travel part of this is well used in transport planning, with analysis often focused, for example, on actual vehicle kilometres travelled or mode share. Capa-

\footnotetext{
${ }^{1}$ The analysis was carried out as part of the British Council Newton Fund Institutional Links project on Sustainable Cities and Resilient Transport (University of Oxford, UCL and De La Salle University, 2015-2017).
} 
bility (the real opportunities, concerning what the person is substantively free to do) is more problematic to measure with an easy metric. It can be viewed as the level of accessibility available (Martens, 2017), but perhaps can be further developed, beyond the aggregate level, as the individual opportunities for travel and participation in activities. Hence the theoretical, aggregate 'physical' accessibility might be modified by issues such as the type of available infrastructure, built form, social and cultural norms, and individual characteristics-and these give the individual a unique capability set. The 'real' opportunities are also difficult for individuals to assess, as they might not be aware of the full or relative range of opportunities on offer. Capability should, however, cover the potential and aspiration to access different activities within particular contextual constraints.

The capability is hence viewed as the substantive freedom to achieve different activities and lifestyles, i.e., the combinations of different possibilities from which the person can choose. For example, a person with a high income may choose to have a similar level of mobility (functioning) to a person with a lower income, but have a very different capability set in that they could choose to be much more mobile. The realised functionings are modified again relative to the capability set according to individual characteristics such as income, disability, education and aspiration. In practice, a higher income is likely to lead to a higher realised functioning in mobility and participation terms. The value in using such a distinction is that this may lead us to understand why certain levels of accessibility-even improved levels of public transport, pedestrian or cycling accessibility-are not being used. The evaluative focus for assessing the social impacts of transport can hence be widened beyond the realised functionings to consider issues of capability. This is perhaps most evident when considering different city or national contexts, where the political, institutional and cultural constraints can be very different, including the use of transport systems.

In terms of applying CA, Sen avoids outlining a basic list of capabilities and giving weights to different capabilities. His reasoning is that different capability sets will be relevant to particular groups in different settings. Others argue that CA is most useful when applied as an evaluative approach and we attempt to build on this in relation to transport. Nussbaum (2003) provides a list of 10 central human capabilities which can be used as the basis for discussion on factors (beings and doings) that may be important in a particular context. These include: life; bodily health; bodily integrity; senses, imagination and thought; emotions; practical reason; affiliation; other species; play; and control over one's environment.

A third core concept in CA is agency, and this is defined as someone who acts and brings about change (Sen, 1999, pp. 18-19). This can be interpreted at the individual or societal levels, including the role of institutions and organisations within particular political and cultural contexts. The agency aspect is important in help- ing to structure and shape the potential for capabilities and functionings. Sen further distinguishes this in terms of opportunity freedom (what opportunities or abilities individuals have to achieve) and process freedom (the process through which activities might happen) (Sen, 1999, p. 17).

CA is interpreted and applied in many different ways in the literature, and most often in relation to development studies. Analysis on deprivation and advantage using CA is focused on capabilities or functionings rather than utility or commodity, hence there is a humancentred and multi-dimensional, pluralistic emphasis. Assessment can incorporate measurement, but more often is focused on qualitative discussion, and is usually focused on either functionings or capabilities, and rarely both together (Comin et al., 2008). The objective of development is seen as the expansion of capabilities, hence there is a concern with changing practice and generating policies and activities which may increase capabilities (Sen, 1999). It is assumed that the functionings would increase alongside the increased opportunities.

Figure 1 interprets and applies CA in the transport context, illustrating how a capability set (including a positive journey experience, such as bodily health, integrity, emotion, affiliation, and access to activities) may be available to an individual, yet only a more limited set of functionings are realised, dependent on ability, income and other potential barriers to take up. Some capabilities may be only partly taken up, e.g., through working part-time; or even be more fully taken up than initially envisaged, e.g., by caring for an elderly relative. Hence there are theoretical, maximum opportunities available, and only some of these are used by the individual. The level of aggregate accessibility may be higher than the capability set-offering a theoretical level of choice to participate in activities that is not always possible to take up. The agency dimension is largely interpreted here at the structural level, including the governmental institutions which may, for example, favour a particular set of infrastructure investments and interventions. This leads to the transport systems and built environment-and frames the available opportunities. The actions of institutions lead, in part, to the opportunities available and help to create the cultural and social norms of travel and participation in activities.

If this is related to a hypothetical example, say investment in a new transport project, it can be seen that levels of accessibility may improve. Alongside, the capability set may increase, including the number and scale of capabilities. Functionings may also increase, depending on the particular context and barriers to take up. There are also issues of adaptive capacity, where individuals modify their beliefs and actions to the context they find themselves in. Individuals hence can normalise both their capabilities and functionings, e.g., the full range of potential opportunities may not be understood or realised.

CA therefore has potential as a conceptual framework which can be used to help understand and repre- 


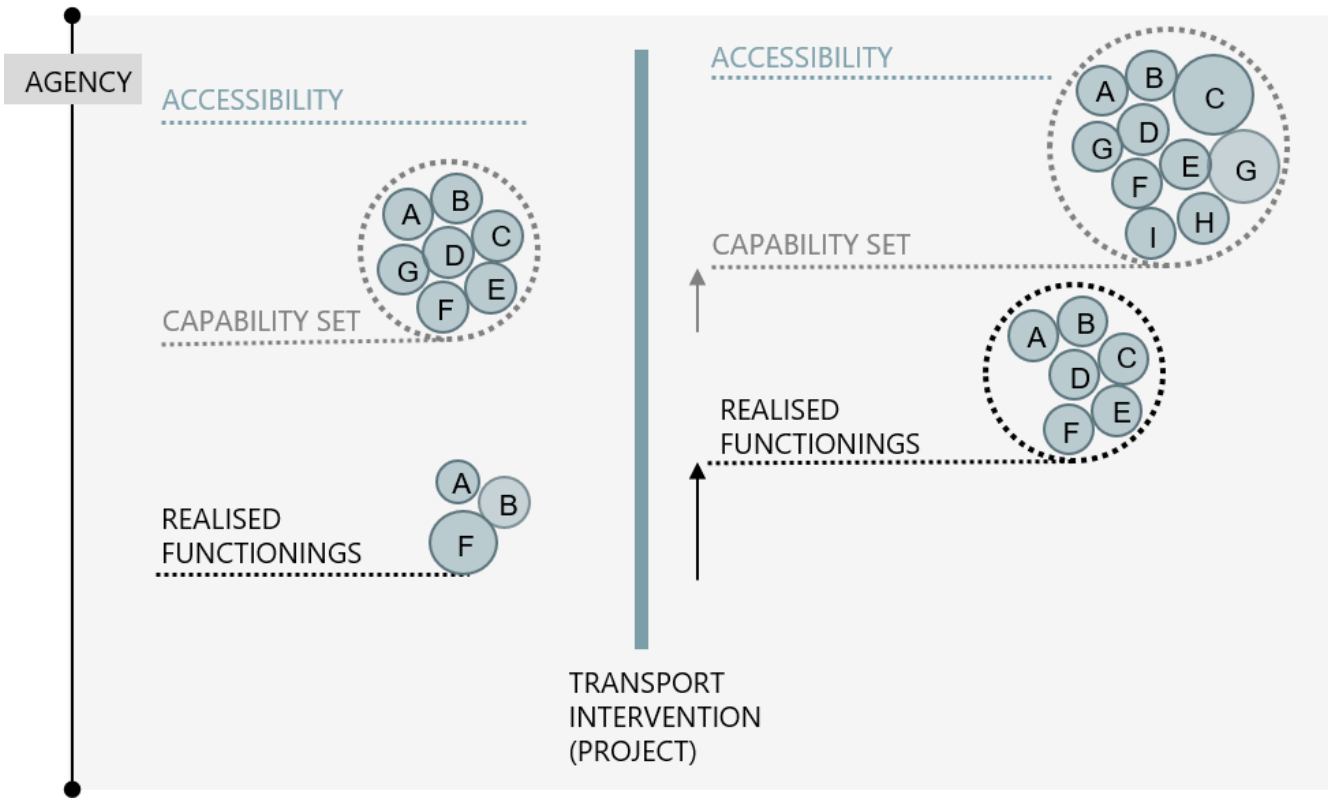

Figure 1. Potential changing functionings and capabilities in relation to a transport project (developing Ryan et al., 2015).

sent travel and activity participation. It could be used alongside accessibility analysis to help understand why and how individuals and societies may participate in activities relative to the barriers to take up. It could be used in social equity impact assessment to understand how proposed infrastructure projects may affect individuals and neighbourhoods. Further research is possible to develop the themes, examining and applying the different concepts, perhaps with most potential through the use of case studies. A more conventional analysis, focused on changes to levels of mobility, such as vehicle kilometres travelled, traffic volume or mode share, in comparison, gives only a limited view of the impacts of transport investment, usually interpreting mobility as a commodity to be consumed. A more human-centred and multi-dimensional analysis can potentially offer greater insights on the social impacts of transport.

\section{Case Study Neighbourhoods and Survey Approach}

The case study neighbourhoods chosen to explore these issues are drawn from Metro Manila, the Philippines (a large urban area, rapidly growing from a population of 1.6 million in 1984, to approximately 12.9 million people in 2015, and estimated to reach 14 million in 2030). There is an urban land area of $614 \mathrm{~km}^{2}$, and high population densities of 21,000 persons $/ \mathrm{km}^{2}$ (Philippine Statistics Authority, 2015). ${ }^{2}$

Metro Manila's diverse and hazard-prone geography-poor transport systems, including high levels of traffic congestion, poor quality public transport, very poor walking and cycling facilities, and dispersed urban population-result in very unequal access to travel and activity participation; challenges to urban life and human development. The private-dominated system of infrastructure provision leads to some types of transport projects being developed, often privately financed urban highway schemes, and extensive public transport networks are very difficult to provide. The metropolitan area is an example of splintered urbanism (Graham \& Marvin, 2010) - where infrastructure provision, transport and urban development lead to fragmented urban experiences and large levels of social and spatial inequality.

The Philippines is seen as medium scale on the Human Development Index (HDI) (with a HDI score of 0.682; 114 out of 188 countries) (United Nations Development Programme, 2016). Per capita GDP in Metro Manila is relatively low at 183,747 Philippine Peso (Php) $(£ 2,877.56$ GBP as at June 2017) (National Statistical Coordination Board, 2013), but this is the highest of the regions in the Philippines. There are an estimated four million slum dwellers (informal settlements) in Metro Manila (Roy, 2014), hence distribution of wealth is very uneven. The richest $10 \%$ of the population account for $30 \%$ of consumption and the poorest $10 \%$ just $3 \%$. The Gini Index 3 is 0.398 (Human Development Network, 2003).

High and low income neighbourhoods were surveyed in Metro Manila (Figure 2). The high income group were interviewed with an online survey, including residents in exclusive villages from around Manila. Respondents were found via university students, staff and wider contacts, using snowball recruitment. This is a useful method where respondents are difficult to find. A variety of high income neighbourhoods were used to source the high

\footnotetext{
${ }^{2}$ As a comparison, Greater London has a population of 8.7 million, land area of 1,572 $\mathrm{km}^{2}$, and population density of 5,518 persons/km² (Office for National Statistics, 2015).

${ }^{3}$ The Gini Index is a measurement of the income distribution of a country's residents. This number, which ranges between 0 and 1 and is based on residents' net income, helps define the gap between the rich and the poor, with 0 representing perfect equality and 1 representing perfect inequality. The World Gini Index is around 0.61; Denmark and Sweden at around 0.25.
} 


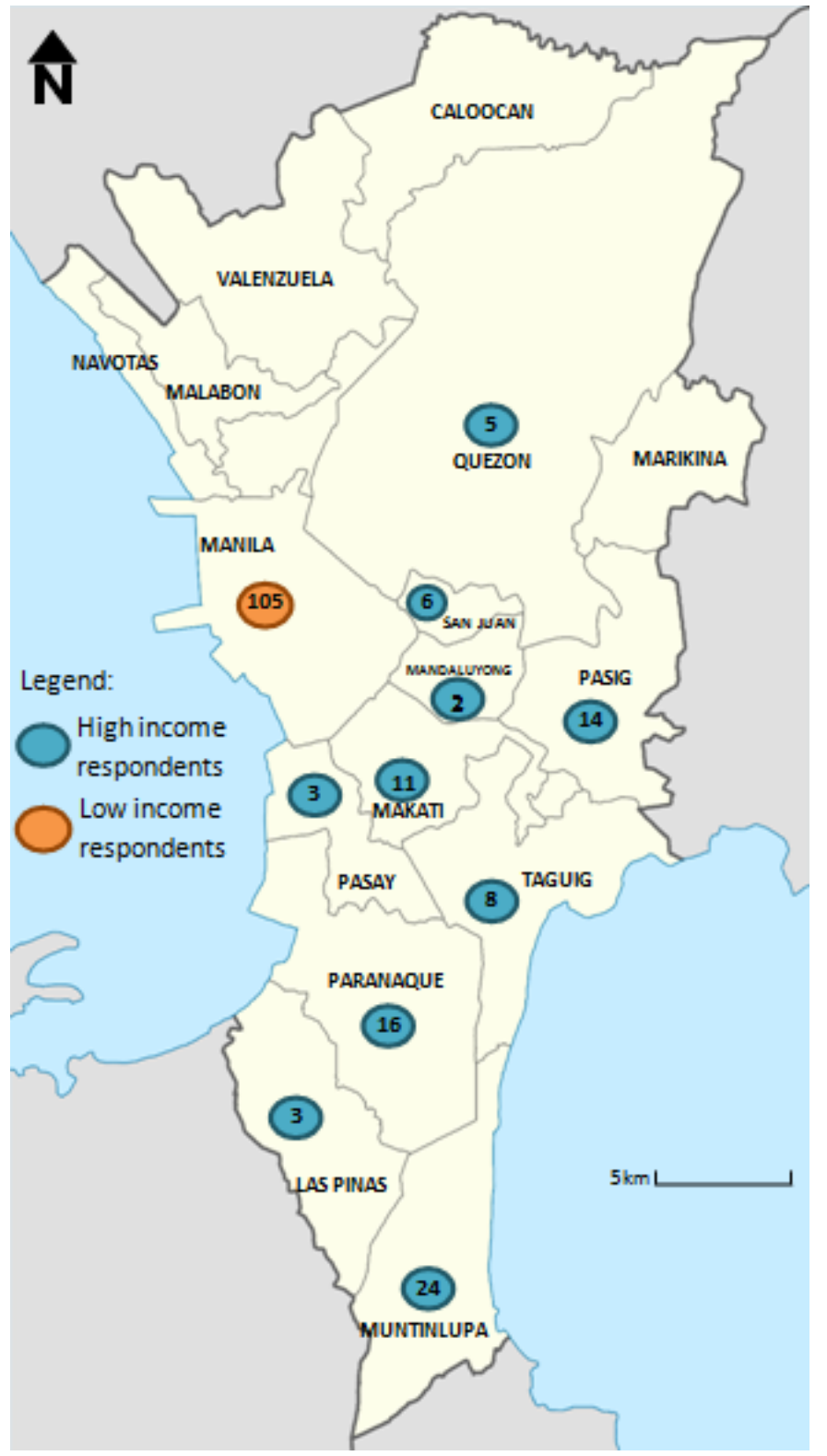

Figure 2. Case study neighbourhoods (high and low income).

income group, again due to difficulty in identifying survey respondents in one neighbourhood. The validity of the survey, in terms of understandability of questions and coverage, was checked initially by members of the academic team involved in the research project and then via a small pilot $(n=10)$ with students at De La Salle University.

Respondents from the high income neighbourhoods generally live in large lots and houses, often with swimming pools and access to private leisure clubs (Figure 3). These exclusive subdivisions were established between the 1940s-1980s; examples are Forbes Park and Urdaneta Village. Houses usually have separate maid's quarters, their own common security personnel, and most own several private vehicles. For exclusive villages near the central business district (CBD), the price could range from Php 150,000 to Php 500,000 per square metre of land, ${ }^{4}$ depending on the year of build. A large house might sell for around 300 million Php ( $£ 4.7$ million GBP). While in other areas further from the Makati CBD, this could range from Php 70,000 to Php 100,000 per square metre of land. These exclusive villages were not converted into commercial uses given their proximity to some of the shopping and business areas of the Makati central business district and the attractiveness for residential living. 102 valid questionnaires were gathered from these high income neighbourhoods.

For the low income neighbourhoods, face-to-face surveys were conducted with respondents in five neighbouring barangays in the Sampaloc District (Figure 4), adjacent to De La Salle University. Surveys were easier to gain in this area, as there were many university students

\footnotetext{
${ }_{4}^{4} 150,000-500,000$ Php per square metre $=£ 2,350-7,800$ GBP (Great British Pounds) per square metre (June 2017 exchange rate).
} 


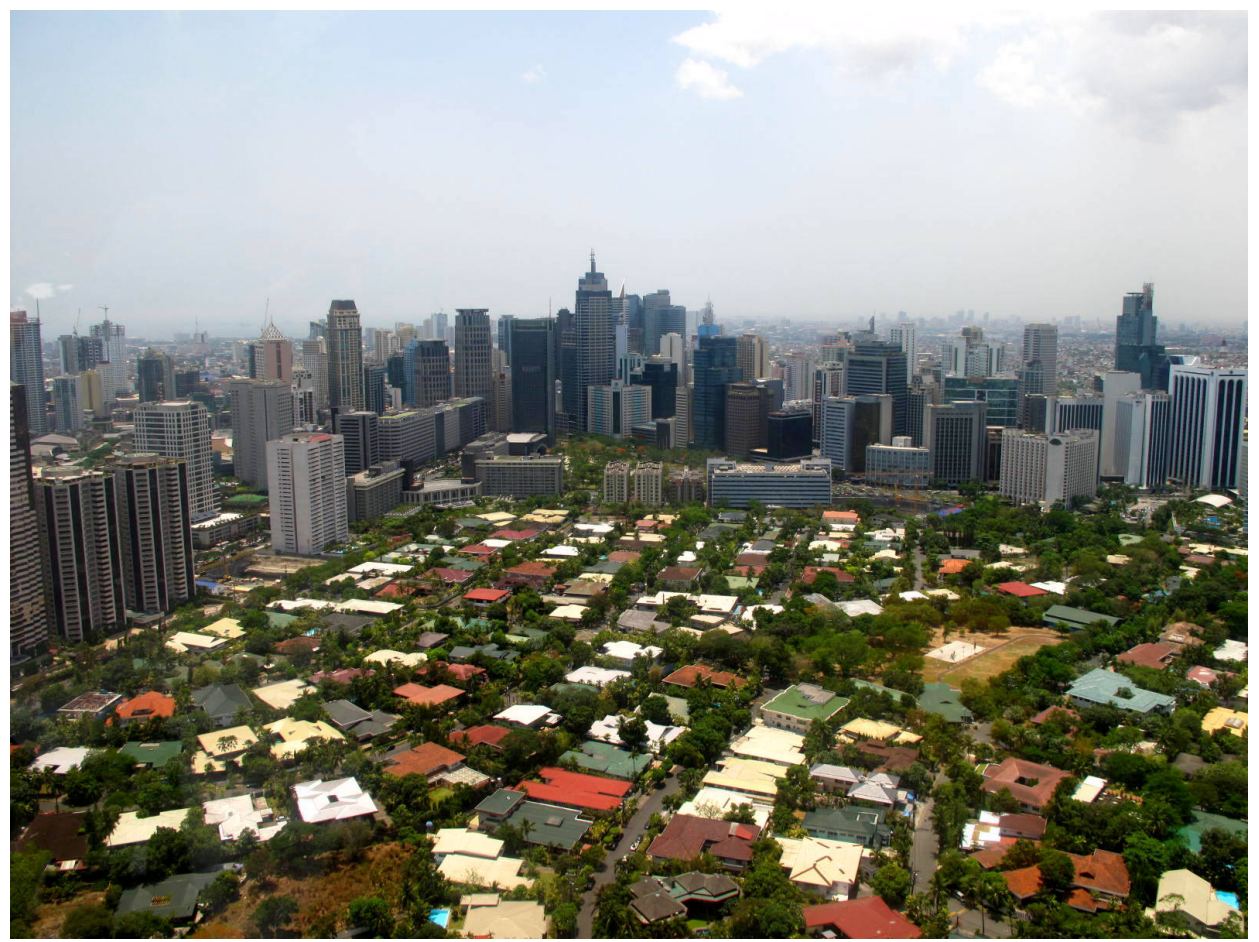

Figure 3. Forbes Park exclusive subdivisions in Makati City (Source: Teoalida, n.d.).

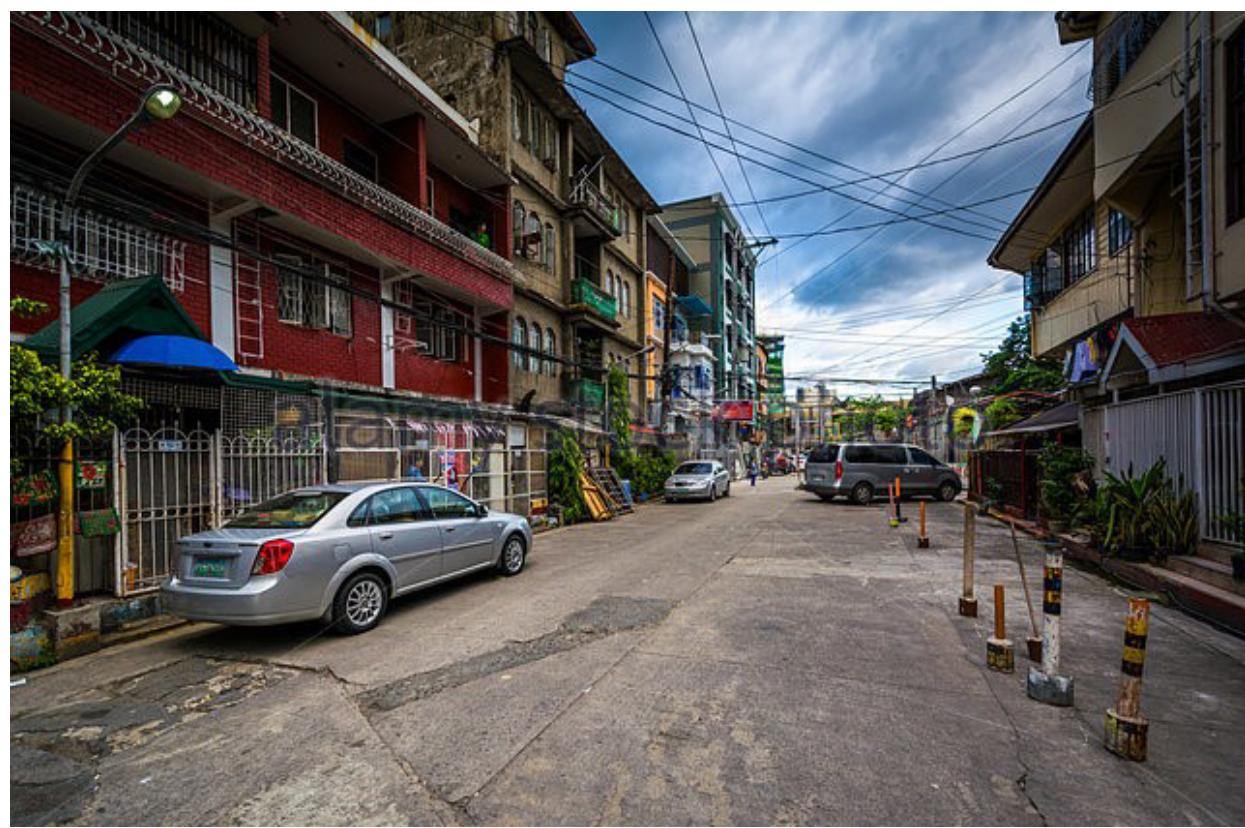

Figure 4. Low income neighbourhood in Sampaloc District (Source: Dreamstime, n.d.).

living here and initial contact was easy to make. Again, snowball recruitment was used. Face-to-face interviews were used to carry out the surveys, instead of the process being online. Not all those being surveyed had easy access to the Internet, hence face-to-face interviews were more appropriate. The same survey was used in the high and low income neighbourhoods, hence it is unlikely that the technique of online and face-to-face delivery affects results, but the impact of this is unknown.

Sampaloc is an old residential neighbourhood; many of the houses are old and dilapidated, and some of these residences have become boarding houses for students. Some residences have converted their ground floor into commercial space for restaurants or stores catering mostly for local residents. Others have replaced their old houses and constructed apartment buildings with four or more storeys for rent to students. There are private car owners in this area, but they usually use the street to park their vehicles as the lot is used for living space. The street in front of the house also sometimes serves as an extension to the house, for example where laundry may be done, or even as an outside liv- 
ing room where people will sit on benches and talk with neighbours. There are also pockets of informal settlers in the area, usually on vacant lots which were not properly secured by their owners. A court order would be required to remove the settlers. The cost of a lot with a structure here would range from Php 35,000 to Php 75,000 per square metre ${ }^{5}$ depending on the age of the house or structure on it. Rent for a flat is available at around 10,000 Php per month ( $£ 160$ GBP per month). A total of 105 valid questionnaires were gathered from Sampaloc. The number of surveys undertaken is low, certainly for quantitative research, but this reflects the context where these were carried out-it is relatively difficult to gain survey respondents in both the high and low income neighbourhoods in Metro Manila. The analysis can be seen as exploratory, with scope for more detailed analysis to follow up some of the initial findings.

\section{Survey Questions}

The surveys included questions on individual and household characteristics, primary and secondary mode of travel (used to access work or main activity), followed by individual views against a range of central human capabilities, covering issues such as travel experience and access to activities. The question themes are based on the list of central human capabilities developed by Nussbaum (2003), but modified to fit the transport and urban planning context in Manila more clearly. Responses are given for desired levels (capability) and actual levels (functioning), using a five-point Likert scale (1 bad; 5 good). The survey is quite lengthy, including 75 questions covering individual characteristics and seven key categories of impact. The survey took around 20 minutes to complete. An example question is given below:

- Capability: What is your desired level of comfort while you are using your primary transport mode?

- Functioning: How do you assess the levels of comfort that you experience while you are using your transport mode?

Following the earlier discussion on applying CA in transport, we rely in the survey on the individual viewpoint of desired level of transport or participation in activities to reflect capability. This may not always relate well to real opportunities, but gives us a view of perceived desired opportunities. Further research can test varied approaches here, including attempts to assess real and relative opportunities-but this is a complex concept and difficult to explain to respondents. The following central human capabilities are used, covering the journey experience, access to activities and also associated well-being:

1. Health, physical and mental integrity:

- Level of stress

- Level of physical activity
- Closeness to other transport users

- Levels of air pollution

- Levels of security (not being assaulted, robbed or harassed)

- Levels of comfort

2. Senses, imagination and thoughts:

- Feelings associated with different modes (such as freedom, insecurity, functionality, enjoyment, health and status)

- Enjoyment of primary and secondary mode

3. Reasoning and planning:

- Access to current employment

- Public transport provision and access to visiting relatives, recreational activities, cultural and sporting activities, etc.

- Range of transport modes

- Affordability of transport modes

4. Social interaction:

- Level of social interaction

- Feeling of discrimination

5. Natural environment and sustainability:

- Presence of natural elements

- Access to sustainable transport modes

6. Information:

- Quality of interchange

- Access to information on transport modes

7. Travel to work and other activities:

- Level of access

- Range of employment

- Commute time

Examining issues such as these allows us to consider the different dimensions of social equity as related to the transport system, the experience of travel and participation in activities. The issues are broader than those usually considered through social impact assessment, including criteria such as senses, imagination and thought; reasoning and planning; and level of social interaction. All of these are potentially important social impacts associated with different transport infrastructure. In particular, the analysis allows us to explore the differences between opportunities and aspiration and realised activities. Hence, neighbourhood types, with high and low incomes, are examined to assess whether there are differences in travel and activities by population cohort and spatially.

\section{Analysis}

There are clear differences between the two neighbourhood types across many of the individual characteristics (Table 1). In the low income neighbourhood, there are more males $(60 \%$ relative to $55 \%$ in the high income neighbourhoods); a different age profile, with less in the $18-24$ group (30\% relative to $53 \%$ ) but more aged 35-54 (34\% relative to $28 \%$ ); lower educational attainment, with fewer at graduate level (42\% relative to $70 \%)$;

\footnotetext{
${ }_{535,000-75,000}$ Php per square metre $=£ 542-1,160$ GBP per square metre (24 May 2017 exchange rate).
} 
Table 1. Descriptive statistics.

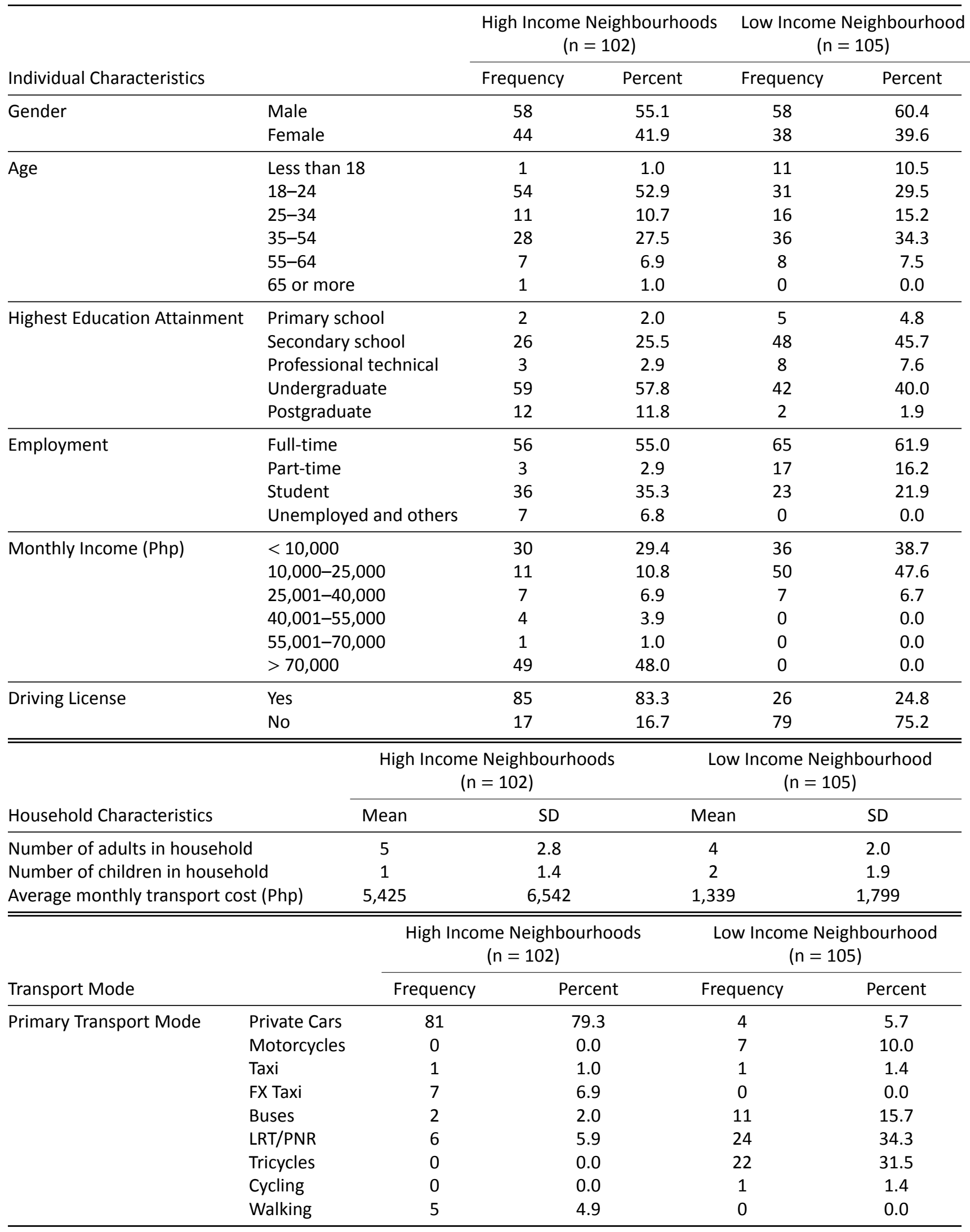


Table 1. Descriptive statistics. (Cont.)

\begin{tabular}{|c|c|c|c|c|c|}
\hline \multirow[b]{2}{*}{ Transport Mode } & & \multicolumn{2}{|c|}{$\begin{array}{l}\text { High Income Neighbourhoods } \\
\qquad(\mathrm{n}=102)\end{array}$} & \multicolumn{2}{|c|}{$\begin{array}{l}\text { Low Income Neighbourhood } \\
\qquad(\mathrm{n}=105)\end{array}$} \\
\hline & & Frequency & Percent & Frequency & Percent \\
\hline \multirow[t]{9}{*}{ Secondary Transport Mode } & Private Cars & 28 & 27.5 & 2 & 2.6 \\
\hline & Motorcycles & 0 & 0.0 & 7 & 9.1 \\
\hline & Taxi & 39 & 38.2 & 1 & 1.3 \\
\hline & FX Taxi & 5 & 4.9 & 1 & 1.3 \\
\hline & Buses & 10 & 9.8 & 5 & 6.5 \\
\hline & LRT/PNR & 4 & 3.9 & 13 & 16.8 \\
\hline & Tricycles & 4 & 3.9 & 21 & 27.3 \\
\hline & Cycling & 2 & 2.0 & 2 & 2.6 \\
\hline & Walking & 10 & 9.8 & 25 & 32.5 \\
\hline
\end{tabular}

Notes: Taxi; FX Taxi (shared White Van taxis, typically for long distance commuting); LRT (Light Rapid Transit), PNR (Philippine National Railway); Tricycles.

a lower monthly income ( $86 \%$ below $25,000 \mathrm{Php}$ per month relative to $40 \%$; and $0 \%$ above $70,000 \mathrm{Php}$ per month relative to $48 \%{ }^{6}$ ); much lower use of the private car (6\% relative to $79 \%)$ and higher use of Light Rapid Transit (LRT) and Philippine National Railway (PNR) systems (34\% relative to $6 \%$ ), and tricycles (32\% relative to $0 \%$, all as a primary mode. The high educational attainment levels reflect the method of survey deliverystudents from De La Salle University were used to gain contacts and gradually find responses. The large differences in incomes and modes used illustrate the large social inequity in Metro Manila.

Figure 5 shows boxplot diagrams of the aggregated capabilities and functionings for the low and high income neighbourhoods. Responses are aggregated to give a combined capability and functioning score across 12 questions, covering level of stress for primary transport, physical activity, closeness to others, air pollution, security, comfort, access to current employment, range of employment in neighbourhood, range of mode options, access to sustainable transport modes, social interaction, and level of information. The other variables are not used due to multicolliniarity and missing data. The maximum possible aggregate score is therefore 60 , for both capabilities and functioning, with a maximum score of 5 under each question. The higher aggregate scores reveal a general increased level of travel experience and access to activities. The boxplots illustrate the distribution of the data by neighbourhood, giving the median (central dark line), interquartile range (box), first and third quartile (edge of box), 1.5 times the interquartile range (the whisker), and minimum and maximum data and outliers (circles).

The high income neighbourhoods appear to have higher levels of both functionings and capabilities, and particularly functionings, relative to the low income neighbourhoods. It is argued that income plays a significant role in shaping capabilities and functionings at an individual level. In other words, lower income groups are likely to have lower rates of participation in various

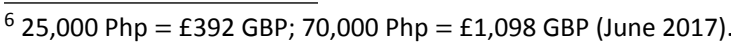

key life activities and are most likely to experience social exclusion. This is what we would expect, and a similar finding to previous literature (Preston \& Rajé, 2007; Social Exclusion Unit, 2003), but measured in a different way in terms of aspired and realised activities - both of these are related to income. This seems a fundamental finding: the current transport systems in Metro Manila are disproportionately affecting lower income groups in social terms. This is also in view of individuals demonstrating adaptive preferences-they are likely to internalise their particular circumstances, choose within a narrow choice set of activities, and not always be aware of the greater possibilities on offer. An important conclusion to be made is that the agency dimensions, i.e., the organisations developing transport strategies and programmes, are not supporting the lower income cohorts to the extent that they might. Perhaps a different set of infrastructure investments are required to support the lower income groups, as well as interventions in urban planning. Again, these issues could be examined with further research, including using different case studies and neighbourhoods.

Table 2 gives additional analysis using the more detailed responses against each dimension on the capability list. Chi-squared tests are used to examine the differences in responses across different population groups with categorical data (gender, age and income) and also spatially (by neighbourhood). The only exception is monthly transport costs, which is continuous data, and an F-test is used to compare mean deviations. Statistically significant findings are indicated with an asterisk.

When examining differences by gender in relation to the 26 indicators, there are only three statistically significant results. Males and females have different perceptions of being assaulted, robbed or harassed (actual) when they are using their primary mode of transport; and levels of social interaction (desired and actual).

There are a number of significant differences by age. Closeness to other transport users (actual), level of trans- 

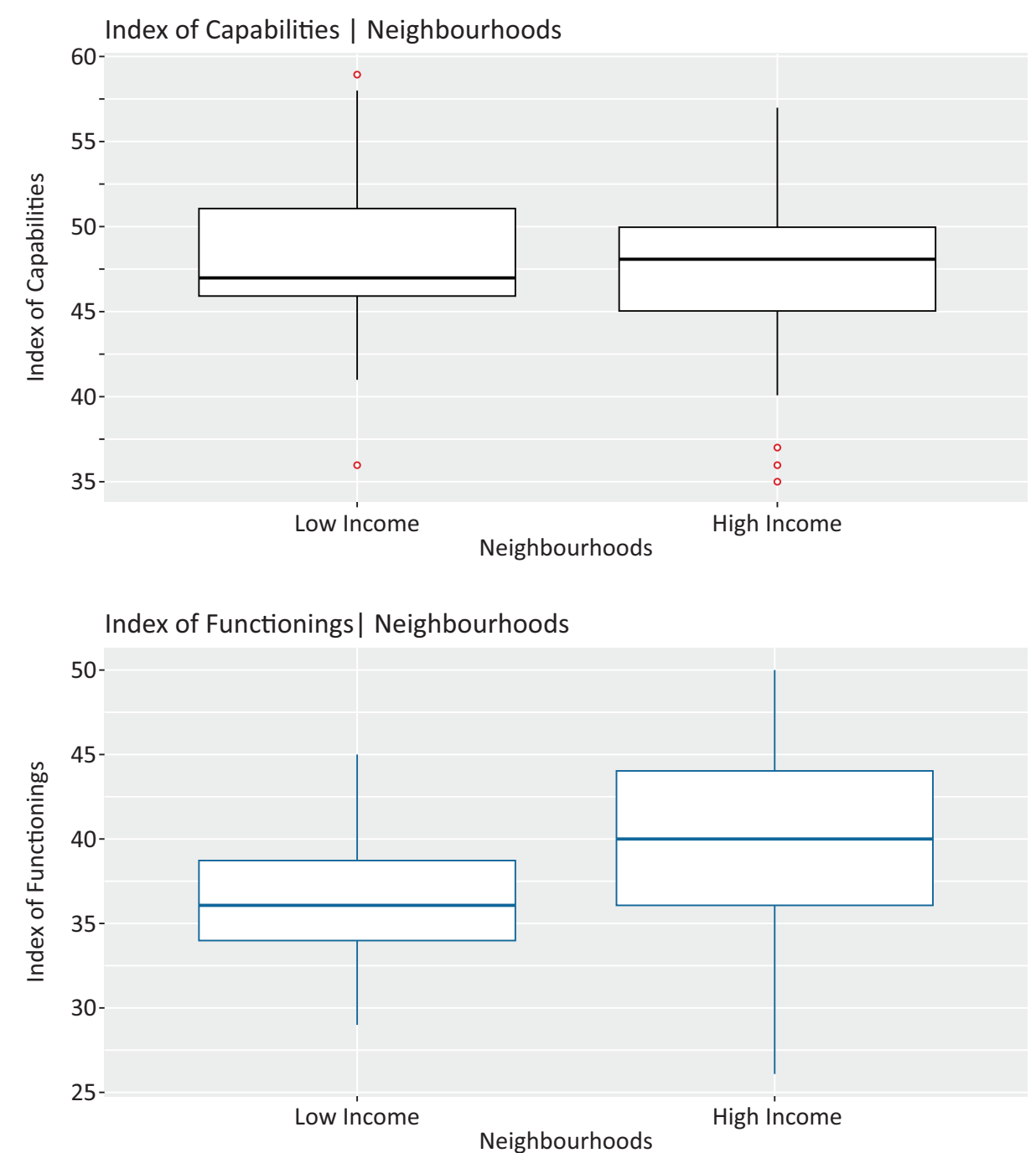

Figure 5. Box plots of index of capabilities and functionings for high and low income neighbourhoods.

port options available (actual), accessibility to transport modes (actual), level of information available (actual), accessibility to employment in local neighbourhood (actual) and monthly transport costs are significant. Examining this in more detail, it is found that people aged between 18-24 are mostly satisfied with the proximity to other transport users when driving cars or taking taxis/FX taxis, but when travelling on public transport, such as LRT/PNR or buses, they tended to feel uncomfortable; the same applies to cycling and walking. Young and middle-aged people are more likely to report having more choice of transport options available to them, when carrying out daily activities, compared with teenagers and older people. Young people are more likely to have access to job opportunities in their local neighbourhoods compared to middle-aged and older people. In addition, older people spend the highest amount on transport costs for their daily commute, followed by middle-aged groups, while the younger generation spend the least on travel costs.

Analyses of the differences by income groups and neighbourhoods (chosen largely by income) yielded many more statistically significant results - almost all of the 26 human capability dimensions, across desired and actual, are significant. Many of these are highly significant ( $p<0.001$ ), particularly between neighbourhoods, including level of physical activity, closeness to other transport users, level of air pollution, security, enjoyment when travelling, accessibility to employment, and level of information available to choose different modes. It can therefore be argued that the parameters of income and location have very significant impacts on individual capabilities and functionings. Of course, the interpretation is complex here-infrastructure, income and travel are closely related. The availability of different types of infrastructure leads to particular types of travel, with the use of infrastructure unevenly distributed over different income groups. But, in addition, the availability of income increases the travel possibilities and the potential to access opportunities. Hence, there are multiple relationships at work, with different factors working in multiple directions. 
Table 2. Summary test statistics (Chi-squared and F Test) for capabilities and functionings.

\begin{tabular}{|c|c|c|c|c|}
\hline & Gender & Age & Income & Neighbourhood \\
\hline \multicolumn{5}{|l|}{ 1. Health, Physical and Mental Integrity } \\
\hline Level of stress (actual)_1.a & 6.564 & 29.223 & $33.069 *$ & $43.229 * * *$ \\
\hline Level of stress (desired)_1.b & 3.901 & 17.067 & 26.044 & $23.620 * * *$ \\
\hline Level of physical activity (actual)_1.d & 4.841 & 21.576 & $51.290 * * *$ & $55.532 * * *$ \\
\hline Level of physical activity (desired)_1.e & 1.686 & 20.673 & $53.998 * * *$ & $50.834 * * *$ \\
\hline Closeness to other transport users (actual)_1.f & 3.520 & $32.103^{*}$ & $44.734 * * *$ & $65.564 * * *$ \\
\hline Closeness to other transport users (desired)_1.g & 1.071 & 25.361 & $48.007 * * *$ & $99.961 * * *$ \\
\hline Level of air pollution (actual)_1.i & 4.164 & 29.897 & 26.290 & $38.143^{* * *}$ \\
\hline Level of air pollution (desired)_1.j & 4.191 & 25.758 & $45.805^{* * *}$ & $61.794 * * *$ \\
\hline $\begin{array}{l}\text { Level of security (not being assaulted, robbed or harassed) } \\
\text { (actual)_1.k }\end{array}$ & $12.671^{*}$ & 19.648 & 25.835 & $47.240 * * *$ \\
\hline $\begin{array}{l}\text { Level of security (not being assaulted, robbed or harassed) } \\
\text { (desired)_1.l }\end{array}$ & 3.174 & 10.117 & $60.253 * * *$ & $49.465 * * *$ \\
\hline
\end{tabular}

\section{Senses, Imagination and Thoughts}

Level of enjoyment when travelling (actual)_2.i

Level of enjoyment when travelling (desired)_2.j

\section{Reasoning and Planning}

Level of accessibility to employment (actual)_3.a

Level of accessibility to employment (desired)_3.b

Level of transport options available (actual)_3.f

Level of transport options available (desired)_3.g

\section{Social Interaction}

Level of social interaction (actual)_4.a

$5.705 \quad 21.837$

$4.591 \quad 27.962$

$48.704 * * * \quad 71.398 * * *$

$29.087 \quad 25.326 * * *$

Level of social interaction (desired)_4.b

\section{Natural Environment and Sustainability}

Level of accessibility to sustainable transport modes (actual)_5.

5.572

3.283

5.605

1.606

22.381

18.709

32.737*

$55.086^{* * *}$

$71.824 * * *$

16.443

13.401

$18.566^{* * *}$

23.392

$71.791 * * *$

27.459

$17.222 * *$

Level of accessibility to sustainable transport modes (desired)_5.d

\section{Information in Transport}

Level of information available to choose alternative transport modes (actual)_6.e

Level of information available to choose alternative transport modes (desired)_6.f

\section{Commuting to Work and Productive Activities}

Level of accessibility to employment in your local neighbourhood (actual)_8.c

Level of accessibility to employment in your local neighbourhood (desired)_8d

\begin{tabular}{lllll}
\hline Commuting Time & 4.413 & 35.905 & $54.150^{*}$ & $29.027^{* * *}$ \\
Monthly Transport Costs $^{(a)}$ & 0.449 & $3.676^{* *}$ & N/A & $37.664^{* * *}$ \\
\hline
\end{tabular}

Notes: $\mathrm{n}=191 ; * \mathrm{p}<0.05, * * \mathrm{p}<0.01, * * * \mathrm{p}<0.001$; (a) as this is a continuous variable, an F-test is used. All other variables are categorical and, as such, a Chi-squared test is applied.

\section{Conclusions}

Transport plays an important role in helping people access activities and participate in life-it is an important factor in human development. But, much of the current transport investment benefits certain cohorts in society, usually the higher income groups, relative to othersand this is experienced in some cities and neighbourhoods more than others. This article has demonstrated how CA might be used in the transport context, using a case study of Metro Manila. It attempts to show what individuals might be able to do and their actual travel and how these might be distributed by population group and spatially. There are critiques of CA and the use of concepts of opportunity, instead of the more orthodox focus on welfarism (the extent to which people's preferences are satisfied). CA is also very difficult to apply, with measurement of opportunity open to different in- 
terpretations, and is complex empirically (Alkire, 2008; Sugden, 2001). But, the Manila context seems to demonstrate that both capabilities and functionings are potentially important. A person's inclusion in and quality of life is not merely a matter of what he or she achieves, or the mobility that is consumed, but also is related to the options available. There is not always a 'genuine' choice of the good life on offer, more a constrained set of options from which to choose (Sen, 1985). The exploratory analysis in this article demonstrates that there are significant differences for travel and activity participation by gender, age, income and neighbourhood; including issues such as travel mode and cost; health, physical and mental integrity; senses, imagination and thought; reasoning and planning. The neighbourhoods studied have very different forms of access to the transport system, the experience of travel, and to the activities this helps reach.

The theoretical framework of CA helps us to understand these issues and can be used to assess what opportunities are available to individuals and what they might like to access (capabilities) versus their actual travel (functionings). The local political and institutional context (agency) helps to explain what transport infrastructure and systems are available to individuals, how the urban form has been developed, and, to an extent, what the societal cultures and norms might be, e.g., whether it is acceptable to walk, cycle, use public transport, or whether the private car is the aspirational mode to use. The distinction between capabilities and functionings might seem to be nuanced, but we argue it is important to add this type of analysis to accessibility planningso that we can further understand why a seemingly good level of accessibility might not be used. In particular, this might be important in a context such as Manila, where use of walking, cycling and public transport is very difficult, uncomfortable, unsafe, and has low status. Hence there are many barriers to using a theoretical level of accessibility. The way we have interpreted capabilities in the surveys is to use this to represent individual aspiration, as related to activities that are feasible to achieve. This could be tested in different ways empirically; and further research could re-examine this issue, perhaps estimating a neighbourhood or societal level of opportunity to travel and participation in activities, using interviews or workshops. This could help to develop a benchmark against which individual functionings could be assessed. In addition, it may be useful to consider different criteria and weighting of criteria, the measurement of adaptive preference by individuals, to compare functionings and capabilities relative to levels of accessibility, and to develop metrics or score thresholds which indicate appropriate or deficient functionings and capabilities. Analysis could be prospective and evaluative-assessing how a project, for example, might lead or has led to a change in opportunity and actual travel.

The application of CA in transport hence has much potential, allowing us to examine the multi-dimensional social impacts of major infrastructure projects and the wider dimensions in using the distinction of capabilities and functionings. This helps us to understand not only the consumption of resources, mobility and accessibility, but also the opportunities that people have in relation to their activity participation. CA does not make the processes of appraisal and evaluation any easier, indeed it makes these much more complex, as there are wider dimensions to be considered. There are many difficulties empirically: in devising surveys that address the wide-ranging social criteria, in explaining the different concepts within CA to respondents, in developing an approach to social impact appraisal that can be scaled up without large resource requirements, and in allowing social impacts to be considered alongside other issues, such as environmental and economic impacts.

The adaptive preference issue is perhaps most difficult-that people may choose their travel and activity participation within a particular set of narrow choice sets, and will not always be aware of the greater possibilities on offer. However, in Manila and elsewhere, differential access to transport and high levels of social inequity remain problematic-and fundamental to human development. Hence, we should continue to refine our approaches to measuring transport's impact on human well-being-and to seek to improve well-being for all groups in society through infrastructure investment. And, as Sen reminds us, this can be considered not only in terms of what people have or can consume, but in terms of what they can do and be.

\section{Acknowledgements}

Thanks to the British Council Newton Fund Institutional Links project on Sustainable Cities and Resilient Transport (University of Oxford, UCL and De La Salle University, 2015-2017) for providing funding for the surveys and analysis. Thanks to Cristina Mirella Villaraza, Deutsche Gesellschaft fur Internationale Zusammenarbeit (GIZ) GmbH, Philippines, who helped with the surveys in the high income neighbourhoods. Finally, thanks to the anonymous reviewers who made very useful comments and significantly strengthened the article.

\section{Conflict of Interests}

The authors declare no conflict of interests.

\section{References}

Alkire, S. (2008). Using the Capability Approach: Prospective and evaluative analyses. In F. Comim, M. Qizilbash, \& S. Alkire (Eds.), The Capability Approach: Concepts, measures and applications. Cambridge: Cambridge University Press.

Ashiru, O., Polak, J., \& Noland, R. (2003). Space-time user benefit and utility accessibility measures for individual activity schedules. Paper presented at the Transportation Research Board. 
Beyazit, E. (2011). Evaluating social justice in transport: Lessons to be learned from the Capabilities Approach. Transport Reviews, 31(1), 117-134.

Church, A., Frost, M., \& Sullivan, K. (2000). Transport and social exclusion in London. Transport Policy, 7(3), 195-205. doi:http://doi.org/10.1016/S0967070X(00)00024-X

Comin, F., Qizilbash, M., \& Alkire, S. (Eds.). (2008). The Capability Approach. Concepts, measures and applications. Cambridge: Cambridge University Press.

Currie, G., Richardson, T., Smyth, P., Vella-Brodrick, D., Hine, J., Lucas, K., . . . Stanley, J. (2009). Investigating links between transport disadvantage, social exclusion and well-being in MelbournePreliminary results. Transport Policy, 16(3), 97-105. doi:http://doi.org/10.1016/j.tranpol.2009.02.002

Currie, G., \& Stanley, J. (2008). Investigating links between social capital and public transport. Transport Reviews, 28(4), 529-547. doi:10.1080/ 01441640701817197

Delbosc, A., \& Currie, G. (2011). Exploring the relative influences of transport disadvantage and social exclusion on well-being. Transport Policy, 18(4), 555-562. doi:https://doi.org/10.1016/j.tranpol.2011.01.011

Dong, X., Ben-Akiva, M., Bowman, J., \& Walker, J. (2006). Moving from trip-based to activity-based measures of accessibility. Transportation Research A, 40, 163-180.

Dreamstime. (n.d.). Retrieved from https://www.dreams time.com/editorial-image-alley-sampaloc-manila-phi lippines-image66572400

Geurs, K., Boon, W., \& Van Wee, B. (2009). Social impacts of transport: Literature review and the state of the practice of transport appraisal in the Netherlands and the United Kingdom. Transport Reviews, 29(1), 69-90. Retrieved from http://www.informaworld. com/10.1080/01441640802130490

Geurs, K., Zondag, B., De Jong, G., \& De Bok, M. (2010). Accessibility appraisal of land-use/transport policy strategies: More than just adding up travel-time savings. Transportation Research Part D, 15(7), 382-393.

Graham, S., \& Marvin, S. (2010). Splintering urbanism. Networked infrastructures, technological mobilities and the urban condition. Abingdon: Routledge.

Hananel, R., \& Berechman, J. (2016). Justice and transportation decision-making: The Capabilities Approach. Transport Policy, 49, 78-85. doi:http:// dx.doi.org/10.1016/j.tranpol.2016.04.005

Hansen, W. G. (1959). How accessibility shapes land use. Journal of the American Institute of Planners, 25(2), 73-76. doi:10.1080/01944365908978307

Human Development Network. (2003). Human Development Index Metro Manila.

Lucas, K. (2004). Running on empty: Transport, social exclusion and environmental justice. Bristol: Policy Press.

Lucas, K. (2012). Transport and social exclusion: Where are we now? Transport Policy, 20, 105-113. doi:http://dx.doi.org/10.1016/j.tranpol.2012.01.013

Martens, K. (2017). Transport justice. Designing fair transportation systems. London: Routledge.

Mella Lira, B., \& Hickman, R. (2017). Using the Capabilities Approach to assess the social impacts of transport projects (Working Paper). London: Bartlett School of Planning, UCL.

Nahmias-Biran, B.-h., Martens, K., \& Shiftan, Y. (2017). Integrating equity in transportation project assessment: A philosophical exploration and its practical implications. Transport Reviews, 37(2), 192-210. doi:10.1080/01441647.2017.1276604

National Statistical Coordination Board. (2013). Per Capita GRDP. Manila: Philippines.

Nordbakke, S. (2013). Capabilities for mobility among urban older women: Barriers, strategies and options. Journal of Transport Geography, 26, 166-174. doi:http://doi.org/10.1016/j.jtrangeo.2012.10.003

Nordbakke, S., \& Schwanen, T. (2014). Well-being and mobility: A theoretical framework and literature review focusing on older people. Mobilities, 9(1), 104129. doi:10.1080/17450101.2013.784542

Nussbaum, M. (2003). Capabilities as fundamental entitlements: Sen and social justice. Feminist Economics, 9(2/3), 33-59. doi:10.1080/1354570022000077926

Office for National Statistics. (2015). Population estimates for UK, England and Wales, Scotland and Northern Ireland. London: Office for National Statistics.

Philippine Statistics Authority. (2015). Census of population: Highlights of the Philippine population. Manila: Philippines.

Preston, J., \& Rajé, F. (2007). Accessibility, mobility and transport-related social exclusion. Journal of Transport Geography, 15(3), 151-160. doi:http:// dx.doi.org/10.1016/j.jtrangeo.2006.05.002

Roy, P. (2014 September 18). In the slums of Manila, inequality is so bad that the worst off have no chance to protest. New Statesman. Retrieved from http://www. newstatesman.com/world-affairs/2014/09/slumsmanila-inequality-so-bad-worst-have-no-chance-pro test

Ryan, J., Wretstrand, A., \& Schmidt, S. M. (2015). Exploring public transport as an element of older persons' mobility: A Capability Approach perspective. Journal of Transport Geography, 48, 105-114. doi:http://doi.org/10.1016/j.jtrangeo.2015.08.016

Sen, A. (1985). Commodities and capabilities. Amsterdam: North-Holland.

Sen, A. (1999). Development as freedom. Oxford: Oxford University Press.

Sen, A. (2009). The idea of justice. London: Allen Lane.

Social Exclusion Unit. (2003). Making the connections. Final report on transport and social exclusion. London: Social Exclusion Unit.

Stanley, J., Hensher, D., Stanley, J., \& Vella-Brodrick, D. (2011). Mobility, social exclusion and well-being: Exploring the links. Transportation Research (Part A), 
45(8), 789-801. doi:https://doi.org/10.1016/j.tra. 2011.06.007

Sugden, R. (2001). Opportunity as a space for individuality: Its value, and the impossibility of measuring it. Ethics, 113(783-809).

Teoalida. (n.d.). Retrieved from http://www.teoalida. com/world/philippines

United Nations Development Programme. (1990). Human development report. New York: United Nations Development Programme.
United Nations Development Programme. (2016). Human development report. New York: United Nations Development Programme.

Woodcock, J., Edwards, P., Tonne, C., Armstrong, B. G., Ashiru, O., Banister, D., . . Roberts, I. (2009). Public health benefits of strategies to reduce greenhousegas emissions: Urban land transport. The Lancet, 374(9705), 1930-1943. Retrieved from http:// www.sciencedirect.com/science/article/B6T1B-4XST PDR-6/2/9dc175af9b047bc03265c583cb5f4b3b

\section{About the Authors}
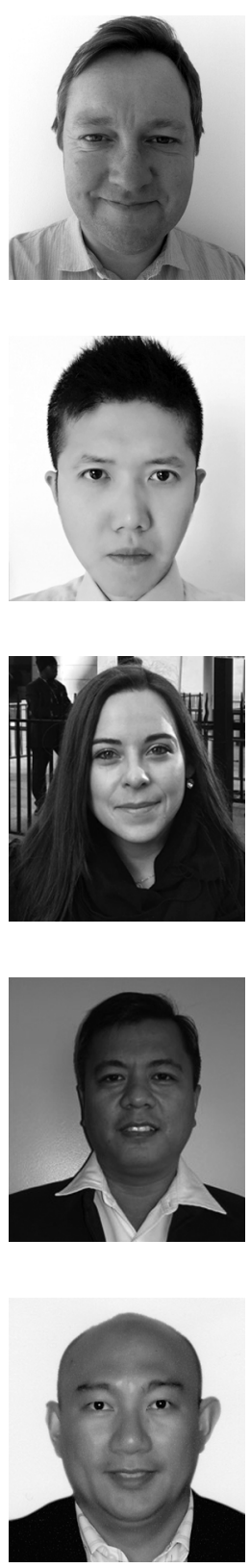

Robin Hickman is a Reader at the Bartlett School of Planning, UCL, and Director of the MSc in Transport and City Planning. He has research interests in transport and climate change, social equity, urban structure and travel, the affective dimensions of travel, discourses in travel, multi-criteria appraisal, and sustainable transport strategies in the UK, Europe and Asia. His most recent books are Handbook on Transport and Development (Edward Elgar, 2015) and Transport, Climate Change and the City (Routledge, 2014).

Mengqiu Cao is a PhD Candidate/Research Assistant at the Bartlett School of Planning, UCL. His research interests include transport-related social equity and travel vulnerability; transport and climate change; freight transport and logistics; urban planning and sustainable development. He has worked as a Research Assistant at UCL for the British Council Newton Fund research project 'Sustainable Cities and Resilient Transport'.

Beatriz Mella Lira is PhD Candidate/Research Assistant at the Bartlett School of Planning, UCL. She is an Architect with a Master's degree in Urban Development from P. Universidad Catolica de Chile. Her research interests are urban and transport planning, wellbeing, social equity, application of the Capability Approach, and multi-criteria appraisal. Beatriz has recently worked as a Visiting Lecturer at University of Westminster, and as a Research Assistant at UCL for the British Council Newton Fund research project 'Sustainable Cities and Resilient Transport'.

Alexis Fillone is a Full Professor in the Transportation Engineering Division, Civil Engineering Department, De La Salle University, Manila. His research interests are in public transportation planning, travel demand modelling, behavioural analysis, as well as environmental issues in transportation. He has several journal publications and is a co-author of Easing Port Congestion and Other Transport and Logistics Issues (Philippine Institute of Developments Studies, 2016).

Jose Bienvenido Biona is the Director of the Center for Engineering and Sustainable Development Research and a Professor of the Mechanical Engineering Department of De La Salle University, Manila. His research focuses mostly on sustainable transport modelling, including market behaviour and technology diffusion, life cycle assessment, technology and policy cost-benefit analysis and development. 